\title{
PERHITUNGAN RUANG TERBUKA HIJAU DI KECAMATAN KARTASURA SUKOHARJO BERDASARKAN LUAS WILAYAH, JUMLAH PENDUDUK, DAN KEBUTUHAN $\mathrm{O}_{2}$
}

\section{Yayi Arsandrie \\ Program Studi Arsitektur Fakultas Teknik Universitas Muhammadiyah Surakarta e-mail: yayi.arsandrie@ums.ac.id}

\section{Enny Widayanti}

Program Studi Arsitektur Fakultas Teknik Universitas Muhammadiyah Surakarta e-mail: ennywiday0521@gmail.com

\begin{abstract}
ABSTRAK
Kecamatan Kartasura merupakan kawasan yang berkembang sangat pesat, hal itu dikarenakan Kecamatan Kartasura mempunyai wilayah yang strategis dan jumlah penduduk yang tinggi. Kepadatan penduduk menjadi latar belakang kebutuhan ruang terbuka hijau atau green open space di Kecamatan Kartasura. Penelitian ini menggunakan metode studi lapangan dengan pengamatan/observasi dan dengan metode perhitungan. Analisis kebutuhan ruang terbuka hijau berdasarkan kepadatan penduduk dan luas wilayah dapat dihitung melalui standar kebutuhan luas RTH (Ruang Terbuka $\mathrm{Hijau}$ ); yaitu sebesar $30 \%$ dari luas wilayah. Kebutuhan ruang terbuka hijau seluas $20 \mathrm{~m}^{2}$ per jiwa diatur dalam Peraturan Menteri Pekerjaan Umum Nomor 05/M/PRT/2008 dan metode Gerarkis digunakan untuk menghitung kebutuhan luas RTH berdasarkan kebutuhan oksigen. Temuan penelitian ini antara lain bahwa: 1) kebutuhan RTH di Kecamatan Kartasura berdasarkan luas wilayah yaitu sebesar 576.9 Hektar, 2) kebutuhan RTH berdasarkan jumlah penduduk Kecamatan Kartasura yaitu sebesar 253.83 Hektar, dan 3) kebutuhan RTH berdasarkan kebutuhan oksigen yaitu sebesar 334 Hektar. Hasil temuan penelitian ini menunjukkan bahwa luas kebutuhan RTH berdasarkan jumlah penduduk dan kebutuhan $\mathrm{O}_{2}$ sudah terpenuhi, namun kebutuhan RTH berdasarkan luas wilayah belum memenuhi standar. Lahan RTH eksisting di Kecamatan Kartasura hanya sebesar 376 Hektar yaitu 19\% dari luas wilayah. Dengan demikian, Kecamatan Kartasura masih membutuhkan RTH sebesar 200.9 Hektar dari luas seluruh wilayah administratif Kecamatan Kartasura.
\end{abstract}

KATA KUNCl: gerarkis, jumlah penduduk, luas wilayah, $\mathrm{O}_{2}, \mathrm{RTH}$

\section{PENDAHULUAN}

Perkembangan suatu kawasan dipengaruhi oleh pola tata bangunan dan jumlah penduduk. Perkembangan kawasan pada umumnya selalu diikuti dengan tingginya pertumbuhan penduduk dan meningkatnya pola permukiman yang padat. Kondisi ini menyebabkan perubahan pada pola penataan tata ruang dan meningkatkan kebutuhan penduduk akan ruang terbuka hijau yang dapat mengurangi dampak negatif dari laju pembangunan di perkotaan.

Ruang terbuka hijau merupakan bagian ruang kota yang berfungsi untuk menciptakan kenyamanan secara visual (Fandeli dkk, 2004). Ruang terbuka hijau kota dapat berbentuk taman kota, hutan kota, atau kawasan rekreasi dan olahraga. Perencanaan ruang terbuka hijau juga sangat bergantung pada penentuan jenis vegetasi di dalamnya. Meskipun demikian, ruang terbuka hijau juga harus memenuhi unsur ekonomi, sosial budaya, dan estetika (Samsudi, 2010). Ruang terbuka hijau merupakan bagian penting dalam perkembangan dan perencanaan sebuah kota. Fungsi utama ruang terbuka hijau yaitu untuk menjamin kenyamanan dan keberlanjutan suatu wilayah, sementara itu fungsi penunjang ruang terbuka hijau dapat ditinjau dari aspek arsitektural, sosial dan ekonomi.

Rencana pengembangan ruang terbuka hijau tahun 1989 menetapkan fungsi-fungsi sebagai di bawah ini:

1. Fungsi RTH sebagai tempat rekreasi dimana penduduk dapat melaksanakan kegiatan rekreasi aktif dan pasif, seperti penyediaan zona tempat olahraga dan taman bermain serta pedestrian.

2. Fungsi RTH sebagai tempat berkarya dan bercocok tanam yang bisa dimanfaatkan untuk membangun sektor pertanian pangan, kebun bunga dan usaha tanaman hias.

3. Fungsi RTH sebagai tempat pemeliharaan, yaitu suatu ruang untuk pengelolaan kota untuk melakukan unsur-unsur suatu perkotaan seperti pemeliharaan jalur sepadan jalan, selokan dan koridor kota.

4. Fungsi RTH sebagai tempat untuk pengaman, yaitu melindungi suatu obyek dari suatu hal yang dapat membahayakan penggunanya 
seperti jalur hijau yang berfungsi untuk melindungi jaringan listrik tegangan tinggi dan jalur sekeliling instalasi militer atau suatu pembangkit tenaga atau wilayah penyangga.

5. Fungsi RTH untuk menjaga pelestarian dan pengamanan lingkungan, yaitu merupakan wilayah konservasi atau preservasi untuk mengamankan kemungkinan terjadinya erosi, pengamanan tepi sungai, serta pelestarian wilayah resapan air.

6. Fungsi RTH sebagai asset pembangunan di masa yang akan datang.

Luas ruang terbuka ideal harus sesuai dengan undang-undang dan peraturan pemerintah, serta dapat memberikan kenyamanan bagi masyarakat sekitar. Beberapa contoh perencanaan ruang terbuka hijau di Kota Surakarta diantaranya adalah: Taman Monumen 45 Banjarsari, ruang terbuka sabuk hijau di tepi bantaran Kali Pepe, Taman Balekambang, dan sabuk hijau di tepian Sungai Bengawan Solo (Samsudi, 2010).

Kecamatan Kartasura pada tahun 2015 memiliki jumlah penduduk sejumlah 96,933 jiwa dengan jumlah pendatang baru tercatat sejumlah 2,199 jiwa (http://kartasura.sukoharjokab.go.id/ tentangkecamatan/2017). Kecamatan Kartasura terletak di Kabupaten Sukoharjo, memiliki 10 desa dan 2 kelurahan (Gambar 1). Dari 12 wilayah tersebut hanya 3 wilayah yang masih memiliki area hijau, yaitu: Pucangan, Ngemplak dan Kertonatan (Muhtarom, 2013).

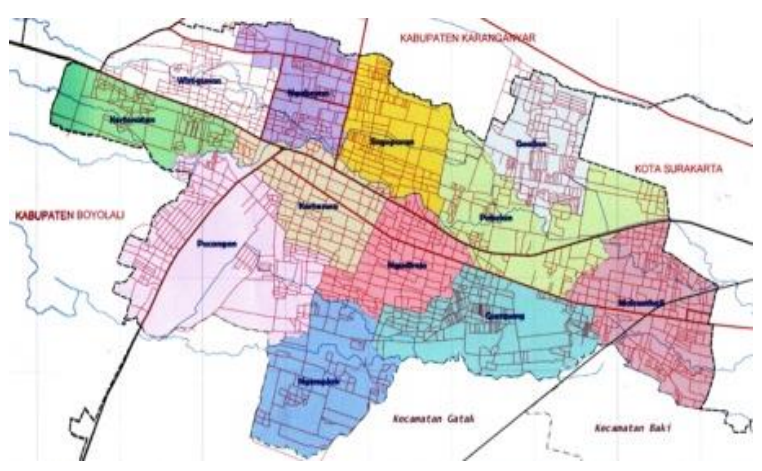

Gambar 1. Peta wilayah administrasi Kartasura (Sumber: kartasura.sukoharjokab.go.id, 2017)

Banyaknya pekerja perusahaan dan mahasiswa di beberapa kampus di wilayah Kecamatan Kartasura membuat kawasan tersebut menjadi semakin padat. Mahasiswa dan pekerja perusahaan sebagian besar berasal dari luar Kecamatan Kartasura sehingga membutuhkan tempat tinggal. Warga sekitar maupun pendatang pun banyak membangun rumah kos, toko, dan tempat makan untuk menambah penghasilan mereka. Selain itu, pertambahan penduduk memicu jumlah kendaraan yang semakin bertambah; sehingga kebutuhan listrik dan bahan bakar pun semakin meningkat. Untuk mengatasi masalah pola permukiman akibat tingginya laju pertumbuhan penduduk dan kebutuhan ruang terbuka hijau maka diperlukan pengelolaan kawasan dan pemanfaatan ruang dengan baik.

Penelitian ini dilakukan untuk memperoleh gambaran mengenai kebutuhan ruang terbuka hijau (RTH) berdasarkan luas wilayah, jumlah penduduk dan kebutuhan $\mathrm{O}_{2}$ di Kecamatan Kartasura. Perhitungan kebutuhan ruang terbuka hijau dilakukan berdasarkan standar peraturan pemerintah agar dapat memberikan kenyamanan yang dibutuhkan oleh warganya.

Penelitian ini diharapkan dapat menjadi bahan rujukan dan perbandingan untuk penentuan kebutuhan ruang terbuka hijau khususnya bagi kawasan-kawasan kota yang mengalami permasalahan lingkungan yang sama. Disamping itu, penelitian ini diharapkan dapat menjadi sumber informasi bagi masyarakat mengenai kebutuhan ruang terbuka hijau agar dapat menjadi rujukan bagi penanganan permasalahan lingkungan di wilayah Kecamatan Kartasura sebagai dampak dari perkembangan kota yang semakin pesat. Hasil penelitian dapat digunakan sebagai bahan pertimbangan bagi Pemerintah Daerah Kecamatan Kartasura untuk menentukan luas kawasan hijau dan lokasi ruang terbuka hijau yang dapat dikembangkan di wilayah perkotaan.

\section{METODE PENELITIAN}

Penelitian ini dilakukan di Kecamatan Kartasura, Kabupaten Sukoharjo, Jawa Tengah. Kecamatan Kartasura terletak di dataran tinggi dengan ketinggian $121 \mathrm{~m}$ di atas permukaan laut. Wilayah Kecamatan Kartasura yang memiliki luas 1,923 Ha berbatasan langsung dengan Kabupaten Karanganyar, Kota Surakarta, Kecamatan Gatak, dan sebelah barat berbatasan dengan Kabupaten Boyolali.

Alat dan bahan yang digunakan dalam penelitian ini yaitu alat tulis dan komputer yang berguna untuk proses pengumpulan data dan analisis data, serta kamera yang digunakan untuk mendokumentasikan hasil survei di Kecamatan Kartasura. Data lain yang diperlukan yaitu peta wilayah dan peta administrasi Kecamatan Kartasura, serta aplikasi google earth.

\section{Pengumpulan Data}

\section{Data Primer}

Pengambilan data primer dilakukan dengan melakukan survei di daerah bervegetasi, serta 
melakukan wawancara kepada masyarakat di sekitar Kecamatan Kartasura.

\section{Data Sekunder}

Data-data sekunder diperoleh dari berbagai instansi dan studi literatur, yang meliputi:

a) Peta administrasi Kecamatan Kartasura.

b) Standar luas ruang terbuka hijau, yang diperoleh dari studi literature.

c) Jumlah penduduk, kepadatan penduduk dan luas wilayah yang diperoleh dari Badan Pusat Statistik (BPS) Kecamatan Kartasura, Kabupaten Sukoharjo.

d) Kebutuhan ruang terbuka hijau berdasarkan luas wilayah, jumlah penduduk, dan konsumsi $\mathrm{O}_{2}$, yang diperoleh dari studi literatur.

\section{Analisis dan Perhitungan}

Analisis perhitungan kebutuhan ruang terbuka hijau dapat dilakukan dengan mempertimbangkan luas wilayah, jumlah penduduk, dan kebutuhan oksigen penduduknya (Gulo, 2008; Pancawati, 2010; Tinambunan, 2006). Perhitungan kebutuhan ruang terbuka hijau berdasarkan luas wilayah dan jumlah penduduk dihitung dengan merujuk pada UndangUndang Penataan Ruang Nomor 26 Tahun 2007 dan Peraturan Menteri Pekerjaan Umum Nomor 05/M/PRT/2008.

Sementara itu, perhitungan kebutuhan ruang terbuka hijau berdasarkan kebutuhan $\mathrm{O}_{2}$ dihitung dengan menggunakan metode Gerarkis (Gulo, 2008; Pancawati, 2010; Tinambunan, 2006). Perhitungan tersebut didasarkan pada jumlah penduduk dan jumlah kendaraan bermotor. Rumus metode Gerarkis adalah sebagai berikut:

$$
\frac{\mathrm{L}_{t}=\mathrm{P}_{\mathrm{t}}+\mathrm{K}_{\mathrm{t}}+\mathrm{T}_{\mathrm{t}}}{(54) \times(0.9375)} \mathrm{m}^{2}
$$

Dimana :

$\mathrm{L}_{\mathrm{t}} \quad=$ merupakan luas RTH tahun ke (t)

$\mathrm{P}_{\mathrm{t}}=$ merupakan jumlah kebutuhan oksigen tahun ke ( $\mathrm{t}$ )

$\mathrm{T}_{\mathrm{t}}=$ merupakan jumlah kebutuhan oksigen pagi kendaraan bermotor tahun ke $(\mathrm{t})$

$\mathrm{Kt}$ = merupakan jumlah kebutuhan oksigen bagi kendaraan bermotor tahun ke $t$

54 = merupakan tetapan yang menunjukkan bahwa $1 \mathrm{~m}^{2}$ luas lahan, menghasilkan 54 gram tanaman perhari.

0.9375 = yaitu konstanta yang menunjukkan bahwa $1 \mathrm{~m}^{2}$ tanaman kering menghasilkan 0.9375 gram oksigen.

Standar kebutuhan oksigen dilakukan agar dapat mengetahui nilai $\mathrm{O}_{2}$ yang dibutuhkan dan karbondioksida yang dikeluarkan sehingga dapat memberikan kenyamanan dan kesehatan bagi masyarakar sekitar. Standar kebutuhan oksigen dan klasifikasi daya minimal kendaraan ditunjukkan pada Tabel 1 dan Tabel 2 berikut ini:

Tabel 1. Ketentuan kebutuhan $\mathrm{O}_{2}$ dan pemakaian bahan bakar

\begin{tabular}{|l|l|c|}
\hline \multicolumn{1}{|c|}{$\begin{array}{c}\text { Konsumsi } \mathbf{O}_{2} \text { manusia per } \\
\text { hari }\end{array}$} & \multicolumn{2}{|c|}{$\begin{array}{c}\mathbf{8 4 0} \\
\text { (gram/hari) }\end{array}$} \\
\hline $\begin{array}{l}\text { Rata-rata pemakaian bahan } \\
\text { bakar (kg/PS jam) }\end{array}$ & Bensin & 0.21 \\
\hline $\begin{array}{l}\text { Kebutuhan oksigen tiap 1 kg } \\
\text { bahan bakar }\end{array}$ & Diesel & 0.16 \\
\hline & Bensin & 2.77 \\
\hline
\end{tabular}

Sumber: Permen PU No: 05/PRT/M/2008

Tabel 2. Klasifikasi dan Daya Minimal Kendaraan

\begin{tabular}{|l|c|}
\hline \multicolumn{1}{|c|}{ Klasifikasi } & Daya Minimal (PS) \\
\hline Sepeda Motor & 1 \\
\hline Mobil & 20 \\
\hline Kendaraan Truk & 50 \\
\hline Kendaraan Bus & 100 \\
\hline
\end{tabular}

Sumber: Permen PU No: 05/PRT/M/2008

\section{HASIL DAN PEMBAHASAN}

Pada tahun 2015, sejumlah $471 \mathrm{Ha}$ atau 24.49\% wilayah Kecamatan Kartasura merupakan lahan sawah dan 1,452 Ha atau sekitar $75.51 \%$ bukan lahan sawah (Gambar 2). Berdasarkan data tersebut, ruang terbuka hijau di Kecamatan Kartasura hanya sebesar $376 \mathrm{Ha}$ atau $19 \%$.

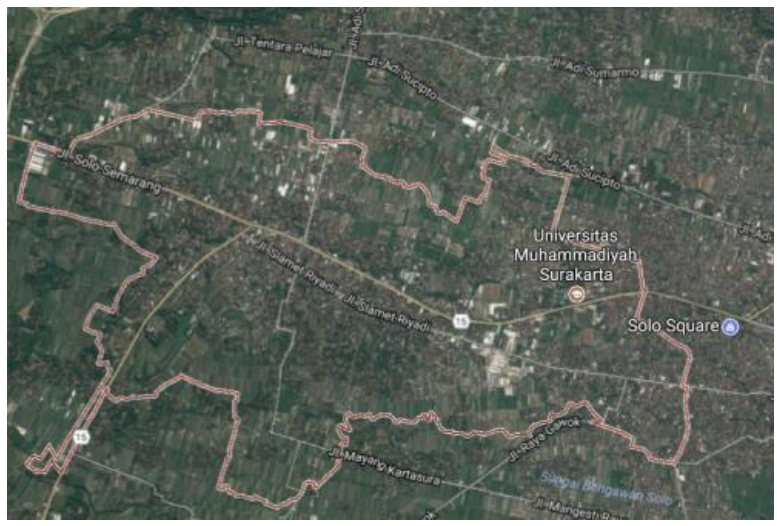

Gambar 2. Peta satelit wilayah Kartasura (Sumber : Google Earth, 2018)

Berdasarkan gambar Rencana Detail Tata Ruang Kecamatan Kartasura Tahun 2012-2032, google earth, dan analisis hasil survei dapat diperlihatkan data penggunaan lahan di Kecamatan Kartasura pada Gambar 3 sebagai berikut: 


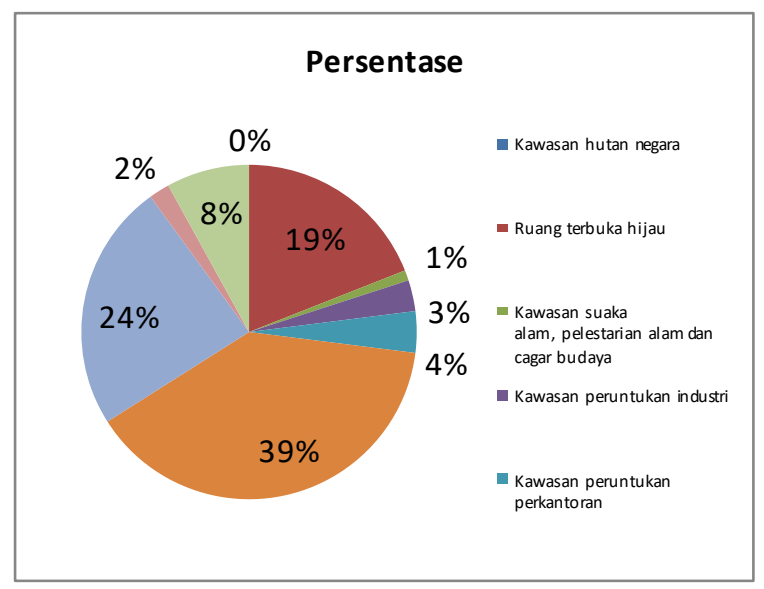

Gambar 3. Penggunaan lahan di Kecamatan Kartasura (Sumber: Hasil analisis penulis berdasarkan data DPU Cipta Karya Jawa Tengah, 2018)

\section{Kebutuhan Ruang Terbuka Hijau Berdasarkan Luas Wilayah}

Menurut Undang-Undang Penataan Ruang Nomor 26 Tahun 2007, proporsi RTH pada suatu wilayah yaitu sebesar $30 \%$ dari luas wilayah administratif kawasan tersebut. Tabel 3 berikut menunjukkan hasil analisis kebutuhan ruang terbuka hijau di Kecamatan Kartasura:

Tabel 3. Analisa Kebutuhan RTH berdasarkan luas wilayah di Kecamatan Kartasura

\begin{tabular}{|c|l|c|c|}
\hline No & $\begin{array}{c}\text { Desa/ } \\
\text { Kelurahan }\end{array}$ & $\begin{array}{c}\text { Luas } \\
\text { Wilayah } \\
\text { (Ha) }\end{array}$ & $\begin{array}{c}\text { RTH yang } \\
\text { dibutuhkan } \\
\text { 30\% dari luas } \\
\text { wilayah (Ha) }\end{array}$ \\
\hline 1. & Ngemplak & 170 & 51 \\
\hline 2. & Gumpang & 192 & 57.6 \\
\hline 3. & Makamhaji & 211 & 63.3 \\
\hline 4. & Pabelan & 131 & 39.3 \\
\hline 5. & Ngadirejo & 121 & 36.3 \\
\hline 6. & Kartasura & 134 & 40.2 \\
\hline 7. & Puncangan & 228 & 68.4 \\
\hline 8. & Kertonatan & 120 & 36.0 \\
\hline 9. & Wirogunan & 133 & 39.9 \\
\hline 10. & Ngabeyan & 118 & 35.4 \\
\hline 11. & Singopuran & 133 & 39.9 \\
\hline 12. & Gonilan & 232 & 69.6 \\
\hline & Jumlah & $\mathbf{1 , 9 2 3}$ & $\mathbf{5 7 6 . 9}$ \\
\hline & Sumber: Analisis dan BPS Sukoharjo, 2017 \\
\hline
\end{tabular}

Dari hasil analisa dan perhitungan pada Tabel 3, luas ruang terbuka hijau (RTH) di Kecamatan Kartasura yang dibutuhkan yaitu sebesar $576.9 \mathrm{Ha}$ dari $30 \%$ total luas wilayah Kecamatan Kartasura, sedangkan ruang terbuka hijau eksisting saat ini sebesar $376 \mathrm{Ha}$ yaitu 19\% dari luas wilayah
Kecamatan Kartasura. Hasil tersebut menunjukkan bahwa kebutuhan ruang terbuka hijau berdasarkan luas wilayah di Kecamatan Kartasura belum tercukupi; Kecamatan Kartasura masih membutuhkan ruang terbuka hijau sebesar $200.9 \mathrm{Ha}$.

\section{Kebutuhan Ruang Terbuka Hijau Berdasarkan Jumlah Penduduk}

Perhitungan kebutuhan ruang terbuka hijau dilakukan dengan mengacu pada Peraturan Menteri Pekerjaan Umum Nomor 05/M/PRT/2008 bahwa kebutuhan kenyamanan penduduk terhadap ruang terbuka hijau sebesar $20 \mathrm{~m}^{2}$ per jiwa penduduk. Analisa kebutuhan ruang terbuka hijau berdasarkan jumlah penduduk di Kecamatan Kartasura ditunjukkan pada Tabel 4 berikut ini:

Tabel 4. Analisa Kebutuhan RTH berdasarkan jumlah penduduk di Kecamatan Kartasura

\begin{tabular}{|c|c|c|c|}
\hline No & $\begin{array}{c}\text { Desa/ } \\
\text { Kelurahan }\end{array}$ & $\begin{array}{c}\text { Jumlah } \\
\text { Penduduk }\end{array}$ & $\begin{array}{c}\text { Standar } \\
\text { Luas RTH } 20 \\
\text { m² }^{2} \text { kapita }\end{array}$ \\
\hline 1. & Ngemplak & 4,678 & 93,560 \\
\hline 2. & Gumpang & 10,042 & 200,840 \\
\hline 3. & Makamhaji & 21,132 & 422,640 \\
\hline 4. & Pabelan & 8,953 & 179,060 \\
\hline 5. & Ngadirejo & 12,835 & 256,700 \\
\hline 6. & Kartasura & 20,104 & 402,080 \\
\hline 7. & Puncangan & 18,275 & 365,500 \\
\hline 8. & Kertonatan & 4,675 & 93,500 \\
\hline 9. & Wirogunan & 5,411 & 108,220 \\
\hline 10. & Ngabeyan & 5,705 & 114,100 \\
\hline 11. & Singopuran & 8,846 & 176,920 \\
\hline \multirow[t]{3}{*}{12 . } & Gonilan & 6,259 & 125,180 \\
\hline & Jumlah & 126,915 & $2,538,300$ \\
\hline & & $=$ & $253.83 \mathrm{Ha}$ \\
\hline
\end{tabular}

Hasil analisa pada Tabel 4 menunjukkan bahwa luas ruang terbuka hijau berdasarkan jumlah penduduk di Kecamatan Kartasura yaitu sebesar 253.83 Ha dari jumlah penduduk Kartasura sebanyak 126,915 jiwa. Angka tersebut menunjukkan bahwa luas ruang terbuka hijau berdasarkan jumlah penduduk sudah terpenuhi. Meskipun demikian, hasil observasi di lapangan menunjukkan bahwa jumlah taman publik masih sangat kurang.

\section{Luasan RTH Berdasarkan Kebutuhan $\mathrm{O}_{2}$}

Data administratif wilayah Kecamatan Kartasura menunjukkan bahwa Kecamatan Kartasura memiliki luas wilayah sebesar 1,923 $\mathrm{Ha}$ dengan jumlah penduduk 126,915 jiwa. Untuk menghitung 
kebutuhan ruang terbuka hijau berdasarkan kebutuhan $\mathrm{O}_{2}$ dengan menggunakan metode Gerarkis, maka harus menghitung kebutuhan oksigen manusia per/hari dan kebutuhan oksigen bagi pengendara kendaraan bermotor per/hari.
Kebutuhan oksigen (gram/hari) yaitu :

Kebutuhan Oksigen $=840 \times 126,915$

Tabel 5. Jumlah kebutuhan $\mathrm{O}_{2}$ bagi pengendara kendaraan bermotor

\begin{tabular}{|l|r|r|r|r|r|}
\hline \multicolumn{1}{|c}{ Jenis } & $\begin{array}{c}\text { Daya } \\
\text { Kinimal } \\
\text { (Ps) }\end{array}$ & $\begin{array}{c}\text { Kebutuhan } \\
\text { Bahan Bakar } \\
(\mathbf{K g} / \mathbf{P s})\end{array}$ & $\begin{array}{c}\text { Kebutuhan } \\
\mathbf{O}_{2} \text { Tiap 1 } \\
\text { Liter BB } \\
(\mathbf{k g})\end{array}$ & $\begin{array}{c}\text { Kebutuhan } \\
\mathbf{O}_{2} \text { (kg) }\end{array}$ & $\begin{array}{c}\text { Kebutuhan } \\
\mathbf{O}_{2} \\
\text { (gram/hari) }\end{array}$ \\
\hline Roda 2 atau 3 & 1.00 & 0.21 & 2.77 & 0.58 & 581.70 \\
\hline Roda 4 atau lebih & 20.00 & 0.21 & 2.77 & 11.63 & $11,634.00$ \\
\hline Jumlah & & & 12.21 & $\mathbf{1 2 , 2 1 5 . 7}$ \\
\hline Rata-Rata & & & 6.105 & $\mathbf{6 , 1 0 7 . 8 5}$ \\
\hline
\end{tabular}

Tabel 6. Jumlah kebutuhan $\mathrm{O}_{2}$ bagi pengendara kendaraan bermotor Kecamatan Kartasura

\begin{tabular}{|l|r|r|r|}
\hline Jenis Kendaraan & $\begin{array}{c}\text { Jumlah } \\
\text { Kendaraan }\end{array}$ & $\begin{array}{c}\text { Kebutuhan } \mathbf{O}_{\mathbf{2}} \\
\text { (gram/hari) }\end{array}$ & $\begin{array}{c}\text { Total Kebutuhan } \mathbf{O}_{\mathbf{2}} \\
\text { (gram/hari) }\end{array}$ \\
\hline Roda 2 atau 3 & 28,142 & 581.70 & $16,370,201.4$ \\
\hline Roda 4 atau lebih & 3,965 & $11,634.00$ & $46,128,810$ \\
\hline Jumlah & & & $\mathbf{6 2 , 4 9 9 , 0 1 1}$ \\
\hline
\end{tabular}

Sumber: Analisis penulis berdasarkan data Permen PU No: 05/PRT/M/2008 (2018)

Dari hasil analisis tersebut maka diketahui kebutuhan oksigen manusia per/hari (Pt) adalah sebesar 106,608,600 gram/hari dan kebutuhan oksigen bagi pengendara kendaraan bermotor perhari adalah sebesar 62,499,011 gram/hari.

Kebutuhan ruang terbuka hijau dihitung dengan metode Gerarkis. Perhitungan tersebut didasarkan pada jumlah penduduk dan jumlah kendaraan bermotor.

Rumus metode Gerarkis adalah sebagai berikut:

$$
\begin{aligned}
\mathrm{L}_{t} & =P_{t}+K_{t} \frac{m^{2}}{(54) \times(0,9375)} \\
L_{t} & =\frac{106,608,600+62,499,011}{(54) \times(0.9375)} \mathrm{m}^{2} \\
L_{t} & =\frac{169,107,611}{50,625} \mathrm{~m}^{2} \\
& =3,340,397.2 \mathrm{~m}^{2} \\
& =334 \mathrm{Ha}
\end{aligned}
$$

$$
\text { Ket : } 1 \mathrm{Ha}=10,000 \mathrm{~m}^{2}
$$

Jadi luasan ruang terbuka hijau yang dibutuhkan berdasarkan kebutuhan $\mathrm{O}_{2}$ ialah sebesar $334 \mathrm{Ha}$.

\section{KESIMPULAN}

Analisis yang telah dilakukan dalam penelitian ini menghasilkan kesimpulan sebagai berikut:
1. Kebutuhan luas RTH berdasarkan $30 \%$ dari luas wilayah Kecamatan Kartasura adalah sebesar $576.9 \mathrm{Ha}$.

2. Kebutuhan luas RTH berdasarkan $20 \mathrm{~m}^{2}$ per jumlah penduduk Kartasura sebanyak 126,915 jiwa sebesar $253.83 \mathrm{Ha}$.

3. Kebutuhan luas RTH berdasarkan kebutuhan $\mathrm{O}_{2}$ dengan menghitung jumlah kendaraan dan kebutuhan oksigen bagi pengendara gram/hari adalah sebesar $334 \mathrm{Ha}$.

Kebutuhan ruang terbuka hijau berdasarkan luas wilayah di Kecamatan Kartasura belum memenuhi standar peraturan yang berlaku, sedangkan kebutuhan ruang terbuka hijau berdasarkan jumlah penduduk dan kebutuhan oksigen sudah terpenuhi. Berdasarkan luas wilayah, Kecamatan Kartasura masih membutuhkan ruang terbuka hijau sebesar 200.9 hektar dengan prosentase sebesar $11 \%$. Di Kecamatan Kartasura juga masih kurang sarana prasarana taman publik untuk kegiatan masyarakat seperti bermain, berolahraga, bersantai dan untuk tempat rekreasi.

Beberapa rekomendasi yang dapat diberikan dalam penelitian ini adalah sebagai berikut:

1. Ruang Terbuka Hijau Publik di Kecamatan Kartasura perlu ditambah lagi agar memenuhi standar kenyamanan bagi penduduk. 
2. Penduduk sebagai pengguna ruang terbuka hijau membutuhkan kecukupan suplai oksigen yang diperoleh masyarakat melalui ketersediaan RTH di perkotaan.

3. Sebaiknya tiap rumah menanam satu pohon agar dapat menambah ruang terbuka hijau.

4. Pemerintah sebaiknya merelokasi beberapa area yang padat penduduk untuk menjadi ruang terbuka hijau publik.

\section{DAFTAR PUSTAKA}

Badan Pusat Stastik Kabupaten Sukoharjo, 2017. Kecamatan Kartasura dalam Angka. Surakarta: BPS Kota Surakarta.

Direktorat Jendral Penataan Ruang, 2008. Pedoman Penyediaan dan Pemanfaatan RTH di Kawasan Perkotaan. Jakarta: Departemen Pekerjaan Umum.

Fandeli, C., Kaharuddin dan Muklison, 2004. Perhutanan Kota. Yogyakarta: Fakultas Kehutanan UGM.

Gulo, B.F., 2008. Analisis Kebutuhan Ruang Terbuka Hijau ( RTH) di Kota Medan. Skripsi. Fakultas Pertanian Universitas Sumatera Utara.

Instruksi Menteri Dalam Negeri No. 14 Tahun 1988 tentang Penataan Ruang Terbuka Hijau di Wilayah Perkotaan.

Muhtarom, A., 2013. Diproyeksi Jadi Kawasan Perkotaan, Lahan Pertanian Kartasura Tersisa 127 Hektare. Solo Pos Online. https://www.solopos.com/diproyeksi-jadikawasan-perkotaan-lahan-pertanian-kartasuratersisa-127-hektare-410350
Pancawati, J., 2010. Analisis Kebutuhan Ruang Terbuka Hijau di Kota Tangerang. Tesis. Institut Pertanian Bogor (IPB).

Peraturan Menteri Pekerjaan Umum Nomor 05/M/PRT/2008.

Samsudi, S., 2010. Ruang Terbuka Hijau Kebutuhan Tata Ruang Perkotaan Kota Surakarta, Journal of Rural and Development, Vol. 1 No. 1.

Tinambunan, R. S., 2006. Analisis Kebutuhan Ruang Terbuka Hijau di Kota Pekanbaru, Tesis. Institut Pertanian Bogor (IPB).

Undang-Undang Penataan Ruang Nomor 26 Tahun 2007.

\section{DAFTAR LAMAN}

http://kartasura.sukoharjokab.go.id/tentangkecamatan

http://semuatentangkota.blogspot.co.id/2009/04/fu ngsi-dan-manfaat-ruang-terbuka-hijau.html $20: 34$

http://paradigmakaumpedalaman.blogspot.co.id/201 2/01/ruang-terbuka-hijau.html $20: 37$

http://www.penataanruang.com/ruang-terbukahijau.html $20: 51$ 